\title{
A construção do pensamento pedagógico em um quintal da globalização
}

\author{
The construction of the brazilian \\ pedagogical thought in a backyard of \\ globalization
}

\begin{abstract}
Marília Faria de MIRANDA*
Resumo: Com este artigo objetivamos comentar o processo histórico de elaboração do ideário pedagógico brasileiro e as influências que o impregnaram. Ele faz parte da revisão de literatura na pesquisa que culminou em nossa tese de Doutoramento ${ }^{1}$. Na introdução do tema discorremos sobre a evolução do processo de Ocidentalização do Mundo, também denominado de Globalização. Delineamos a explicação do entendimento da Nova Ordem Mundial como sendo a organização do mundo em uma grande aldeia global (concretizada por meio da internacionalização da economia, bem como da revolução informacional). Desse modo, cada país seria um quintal dessa Aldeia e, o Brasil, "um quintal da globalização". Nessa estrutura, as implicações da atual fase, matizam a reorganização do pensamento pedagógico nos diversos quintais do mundo e, inclusive no Brasil - objeto de reflexões neste texto. Por meio do estudo de diversos autores, no decorrer do trabalho, demonstramos que a influência e a interferência das organizações políticas e econômicas globalizadas têm se mostrado presentes na história brasileira, em todas as áreas componentes da Sociedade e em todas as reformas educacionais, ao longo do seu percurso. Entendemos que, além dessas nossas reflexões, muitas outras questões educacionais demonstram o quanto a educação escolar ainda é incipiente, precária e, assim também, o pensamento pedagógico brasileiro. Concluindo: estas constatações contribuirão para se documentar a evolução da educação escolar remetendo ao tema proposto. Em outras palavras, julgamos importante investigar a expressão do pensamento pedagógico brasileiro nos contextos regionais e locais na contemporaneidade, sendo este o tema de nossas pesquisas nos últimos anos.
\end{abstract}

Palavras-chave: Pensamento pedagógico brasileiro. Educação brasileira. História da Educação. Políticas Educacionais.

\footnotetext{
* Doutora em Educação pela UNESP de Marília. Professora do Departamento de Educação e Mestrado em Educação da Universidade Estadual de Londrina. mmiranda@ sercomtel.com.br ${ }^{1}$ Tese de Doutorado intitulada NUM QUINTAL DA GLOBALIZAÇÂO: reflexos do processo de ocidentalização do mundo na educação brasileira de ensino médio.UNESP, Marília - SP, 2000.
}

Olhar de professor, Ponta Grossa, 9(2): 229-249, 2006. 
Abstract: The aim of this article is to comment on the historical process of elaboration of the Brazilian pedagogical thought and the influences that it received. The article is part of the literature review of my doctoral thesis. In the introduction the evolution of the process of Westernization of the world, also known as Globalization is discussed. The article also presents an understanding of the New World Order as being the organization of the world in the form of a big global village (which becomes a concrete thing by means of the internationalization of the economy as well as of the information revolution). In this perspective, each country would be the backyard of the Village and, Brazil, "a backyard of globalization". In this structure, the implications of the current phase influence the reorganization of the pedagogical thought in the various backyards of the world, including Brazil, which is the object of reflection of this article. By studying various authors during the research, it is possible to demonstrate that the influence and the interference of the political organizations and globalized economies are present in the Brazilian history in all areas that form its society and in all educational reform throughout their existence. In addition to my reflections, many other educational issues demonstrate how incipient and precarious school education is, and also the Brazilian pedagogical thought. In conclusion, the findings will contribute to document the evolution of school education. In other words, it is important to investigate the expression of the Brazilian pedagogical thought in contemporary regional and local contexts.

Keywords: Brazilian pedagogical thought. Brazilian education. History of education. Educational politics.

O campo de estudos em que transitamos tem sido o das políticas educacionais. O problema norteador das nossas pesquisas refere-se à compreensão do processo histórico que perpassa a efetivação do ideário pedagógico como eixo delineador da educação brasileira. O texto que segue constitui parte da revisão de literatura de nossa tese de Doutorado intitulada "Num quintal da globalização: reflexos do processo de ocidentalização do mundo na educação brasileira de ensino médio", defendida na UNESP, campus de Marília, SP (MIRANDA, 2000). Esses estudos têm sido utilizados como suporte às pesquisas realizadas por nós, nos últimos anos, in- vestigando a expressão do pensamento pedagógico brasileiro na formação de professores em nível médio na cidade de Londrina, Paraná (MIRANDA, 2001).

Entendemos que para compreender, analisar e reelaborar com seriedade os embates, gerados contemporaneamente, na tentativa de aprimorar o pensamento pedagógico brasileiro, necessitamos de dois procedimentos: $1^{\circ}$ ) contextualizar a educação em sua própria época; $2^{\circ}$ ) pesquisar as suas raízes históricas e políticas. Neste texto, objetivamos seguir resumidamente estes entendimentos, para apreender os matizes que envolvem a composição do pensamento pedagó- 
gico brasileiro.

\section{A ALDEIA GLOBAL}

Seguindo essa linha de raciocínio, consideramos ser importante entender a constituição política do tempo presente e os seus impactos sobre a educação. Verificamos que a Nova Ordem Mundial atualmente imperante - também denominada de "Globalização" ou "Ocidentalização do Mundo"2 - foi prevista por McLuhan (1968) como sendo a organização do mundo em uma grande aldeia global. Os países se relacionariam de forma a serem parte integrante dela e seus quintais não teriam fronteiras. A imagem do mundo como uma Aldeia Global nos provoca a análise de que, nessas condições, não haveria delimitações geopolíticas. Não havendo divisórias, cada nação compartilharia o seu quintal com as demais.

Nesse entendimento, cada país seria um quintal dessa Aldeia e o Brasil assim também poderia ser visto, ou seja, como "um quintal da globalização". Contemporaneamente, a previsão se concretiza por meio da internacionalização da economia, bem como da revolução informacional conforme o diz Lojkine (1995):

Este fim de século, no entanto, acena com uma mutação revoluci- onária para toda a humanidade, mutação só comparável à invenção da ferramenta e da escrita, no albor das sociedades de classes, e que ultrapassa largamente a da revolução industrial do século XVIII. A revolução informacional (...) está em seus primórdios. Ela é, primeiramente, uma revolução tecnológica de conjunto, que se regula à revolução industrial em vias de terminar. Mas é muito mais que isto: constitui o anúncio e a potencialidade de uma nova civilização, pós-mercantil (p. 11).

A mutação revolucionária, referida por Lojkine (Op. cit.), manifesta-se por meio de relações que se apresentam globalizadas, planetárias e se caracterizam, entre outros aspectos, por questões como: a internacionalização da economia, a tentativa de adoção e utilização de uma língua e de uma moeda universais e a alteração das fronteiras geopolíticas tradicionais, como a queda do muro de Berlim, por exemplo. As inter-relações instauradas, neste tempo histórico, causam a interdependência planetária dos Estados-Nações (SANTOS et al, 1994).

Esses ideais têm atravessado os séculos, como podemos rever em Ponce (1995) o comentário sobre a utilização de uma língua universal e a homogeneização da cultura no pas-

\footnotetext{
2 Entendemos "Globalização" como a queda das fronteiras geopolíticas, numa visão de unificação dos Estados-Nações, imaginando a possibilidade de extinção dos nacio-nalismos em que o cidadão se torne "cidadão do mundo" e o governo seja universal. A "ocidentalização do mundo" refere-se à universalização dos hábitos e costumes ocidentais.
}

Olhar de professor, Ponta Grossa, 9(2): 229-249, 2006. $\overline{231}$ 
sado, temas que estão entre as exigências da atual fase do processo de "OCidentalização do Mundo". Esse autor afirma que: "O Renascimento se propôs formar homens de negócios que também fossem cidadãos cultos e diplomatas hábeis. Uma língua universal, um tipo uniforme de cultura, a paz perpétua, eis as aspirações de Erasmo (1467-1536) e do seu tempo" (op cit, p. 110, grifo nosso).

Análises históricas, com propósito de realizar constatações como essa, demonstram-nos que a construção, desse processo de "ocidentalização mundial", vem sendo realizada através de um longo percurso que coincide com a história do mundo ocidental. E, sob o ponto de vista ideológico, o seu embrião foi gerado no século XI, com e pela expansão do poder da Igreja Cristã (DEL ROIO, 1998).

A materialização do movimento que esse processo gerou é denominada capitalismo, cujo marco inicial ocorreu no século já citado e o seu desenvolvimento deu-se através das grandes invenções e navegações. Desde então, passamos por quatro fases: o Mercantilismo, o Colonialismo, o Imperialismo e, agora, vivemos o Globalismo, ou Ocidentalização do Mundo (IANNI, 1992).

Este fenômeno ocidentalizador do mundo tem-se efetivado, até os dias atuais, como um processo de desenvolvimento desigual, tanto no que se refere aos países, quanto a grupos ou indivíduos. Fundamentado na competitividade, consolidou-se no século
XX, desde a Segunda Guerra Mundial. Tem sido coordenado por organizações internacionais e fortalecido durante a Guerra Fria, usufruindo suas mais recentes vitórias com a queda do muro de Berlim, a reunificação da Alemanha, a derrocada do que se denomina "socialismo real" e a ascensão do Japão (KURZ, 1993).

Os primeiros organismos internacionais a serem constituídos, na condição de administradores desse processo, o foram sob a liderança dos países economicamente mais poderosos e que compõem o denominado Primeiro Mundo, ampliando a tentativa de supremacia dessa história do Capitalismo. Desde então, o processo de globalização - ou ocidentalização planetária - tem sido coordenado por esses órgãos supra-nacionais, "os novos senhores do mundo" nos dizeres de Chomsky (1993).

Essas organizações - ONU, UNESCO, FMI, e suas filiais na América Latina: CEPAL (Comissão Econômica para a América Latina), OREALC (Organização Regional de Educação para a América Latina e Caribe), CINTEFOR (Centro Interamericano de Educação e Formação Profissional) ao coordenarem as relações internacionais, assumem a tarefa de organizar elaborações teóricas e diretrizes políticas, econômicas e pedagógicas, para os países em desenvolvimento, como é o caso do Brasil (FRIGOTTO, 2001).

É na época presente que esse fenômeno está sendo alinhavado, con- 
cretizando a mobilização interativa dos Estados-Nações, em nível planetário, na forma de agrupamentos em blocos. Os dirigentes do mundo globalizado - a quem Chomsky (1993) denomina "Senhores do Mundo" - interferem na governabilidade e nos destinos da educação nacional de cada país.

Assim, as implicações desta atual fase, matizam a reorganização do pensamento pedagógico nos diversos quintais do mundo e, inclusive, no Brasil - objeto de considerações neste texto. Um reflexo desse momento histórico está na exigência do aumento da escolaridade mínima requerida a cada trabalhador ampliando, no contexto histórico contemporâneo, o conceito de educação básica compreendida até o $2^{\circ}$ grau completo ${ }^{3}$.

O princípio, que está por trás das propostas educacionais maiores, mundiais e internacionais, é fundamentado em uma lógica de mercado. A educação, sob esta perspectiva, é entendida como um bem de consumo a ser comprado por quem a queira adquirir. Esse entendimento exclui a maioria da população que, se não a puder receber gratuitamente, como uma prestação de serviço pelo Estado, terá eliminada a sua possibilidade de inserção na sociedade do seu tempo.

Entretanto, há diferentes necessidades e diferentes respostas ocorrendo em diferentes etapas, conforme as potencialidades locais, nacionais. No Brasil, essas respostas têm ocasionado uma revisão do sistema educacional, tanto em nível federal, como estadual e municipal. $\mathrm{O}$ mesmo pode ser verificado em redes de estabelecimentos de ensino oficiais e/ou em instituições particulares.

\section{QUEQUINTALÉESSE?}

O nosso país foi incorporado à história da "Ocidentalização do Mundo" desde 1500. Essa incorporação foi motivada pela ambição dos "desbravadores" da "terra descoberta". As marcas dos "incorporadores" incrustraram-se nos diversos recantos desse "Quintal", durante o decorrer do percurso histórico dos quinhentos anos. Nesse período, também o processo de Globalização evoluiu, expandiu-se e foi se modificando (IANNI, 1992).

Na história brasileira, a influência e a interferência das organizações políticas e econômicas globalizadas têm se mostrado presente em todas as áreas componentes da Sociedade (CANO, 1994) e em todas as reformas educacionais, ao longo do seu percurso (FRIGOTTO, 2001).

As políticas educacionais que delineiam historicamente o pensamento pedagógico brasileiro, têm sido inspiradas em ideários concretizados fora

\footnotetext{
${ }^{3}$ Atualmente se denomina esse grau da educação escolar brasileira de Ensino Médio, de acordo com a nova LDB nº 9.394/96 - como já ocorre em muitos países, por influência do processo de ocidentalização do mundo, de acordo com autores como Bonitatibus (1991) e Bruno (1996), entre outros.
} 
do Brasil ou em instituições não-oficiais. Para efetivá-las, sempre foi necessário o deferimento do Estado, numa relação de submissão da educação à ação autoritária do poder governamental, tanto na organização como na legislação, no controle, no financiamento e na determinação das atividades que têm norteado o saber pedagógico (FREITAG, 1994).

As organizações internacionais coordenam a implantação de políticas nacionais que julgam convenientes. $\mathrm{Na}$ área educacional brasileira, as políticas acordadas denotam-se consolidadas e implantadas, legal e oficialmente, pelas ações do Ministério da Educação, em busca de sua territorialização. Esta adaptação se aprimora com as propostas complementares advindas das Secretarias de Educação dos Estados e dos Municípios (MIRANDA, 1995; LAUGLO, 1997).

\section{A CONSTRUÇÃO DAS IDÉIAS PEDAGÓGICASNO BRASIL}

O pensamento pedagógico brasileiro foi elaborado durante o percurso de seus quinhentos anos de história. Essa elaboração foi incorporando, ao longo do tempo, os conceitos teóricos e práticos de educação trazidos pelos seus colonizadores-construtores, sofrendo modificações no jogo de forças entre os grupos de poder que se têm sucedido, de tempos em tempos.

A pluralidade das influências recebidas, no decorrer do processo his- tórico, tem desenhado um perfil peculiar da educação brasileira. Cada região a territorializa, ou seja, implanta e assimila as novas propostas, de acordo com os seus entendimentos e com as suas singularidades regionais. O movimento evolutivo, gerado por descobertas novas nos diversos campos das ciências e formas inovadoras de recriação do existente, provoca releituras das heranças históricas do que se entende por educação e de que qualidade se requer a ela.

Com esse entendimento, para analisar o pensamento pedagógico brasileiro precisamos contextualizá-lo, não apenas no tempo presente, mas na história que o construiu. E esta remete-nos de pronto, aos resultados que o trajeto foi consolidando, à maneira como foi moldando o modo de pensar sob o ponto de vista cultural e à forma como atingiu, ou não, a escola e as ações pedagógicas desenvolvidas no interior dela. Algumas das marcas cravadas ao longo do tempo são visíveis em todos os recantos desse "Quintal", o Brasil. De Norte a Sul, os efeitos desse processo histórico se fazem presentes e, alguns deles, podemos aqui destacar como sendo:

- a exploração e depredação das riquezas naturais, a extinção da fauna e da flora deste país-continente, tão bem aquinhoado de belezas naturais que, irresponsavelmente, são destruídas de diversos modos;

- a espoliação da maior riqueza de um povo, as suas crianças, através 
do trabalho precoce e da prostituição infantil desde a mais tenra idade, maculando essa expressão de força e de futuro;

- o desenvolvimento de regiões inteiras, fundamentado numa filosofia contraventora, marginal, de dominação e de opressão do povo, utilizando a sedução do progresso industrial, científico e tecnológico, que atrai para os grandes centros e subjuga os migrantes de recantos esquecidos;

- o nativo, dono da terra, tem carregado esse fardo histórico, assistindo com o 'coração partido' ao hasteamento da bandeira dos 'novos donos'. Para suportar todo esse peso, só mesmo a fé no poder amoroso de uma 'Mão Transcendental' (MIRANDA, 2000).

Mas esse povo, formado por um colorido de raças, sonha e realiza com dedicação a parte que lhe cabe na construção desse "quintal da globalização". Tem usufruído muito pouco da grandiosa obra já realizada, em meio a tantas mazelas, à geral excrescência e à admiração pelas "ilhas de excelência” que constrói com suas mãos e das quais tem sido excluído.

Do pensamento pedagógico brasileiro, pouco tem se aproximado e usufruído. À cidadania, que é seu direito, ainda não tem tido acesso, por muitos motivos e, entre eles, a educação ocupa um lugar de destaque.

E o desespero, a impotência e a perplexidade desse povo, atônito, enche os templos, das mais variadas denominações religiosas. Qualquer um pode verificar essas constatações na prática de sua observação quotidiana, ou na teoria com a leitura de autores como Machado (1994).

Com o objetivo de democratizar a educação escolar, várias propostas têm se sucedido. As mais notáveis transformações decorrentes dessas tentativas são recentíssimas, iniciaram-se após a segunda década do século XX e só se tornaram expressivas na segunda metade do mesmo século. Mesmo assim, ocorriam apenas nos grandes centros, só foram estendidas para a maior parte do território nacional há poucas décadas e ainda ocorrem com grande precariedade.

Durante esse período, deparamonos com um agitado processo na tentativa de conseguir a melhoria da educação escolar. Ao mesmo tempo, tem sido destacada a tentativa de democratização das relações entre educadores e educandos, através de vários movimentos de luta (SAVIANI, 1984).

Verificamos que, no decorrer dos cinco séculos de história do Brasil, os movimentos organizados em prol da Educação registraram, em seu bojo, transformações ideológicas locais, que deram um colorido à brasileira às idéias pedagógicas trazidas do exterior. Ao se implantarem em território brasileiro, refletiram as transformações mundiais, contribuindo para a proliferação de diversas correntes pedagógicas e para embrionar outras que atravessaram o século, com manifestações sociais e ideológicas va- 
riadas como, por exemplo:

- o movimento dos pioneiros da Escola Nova que eclodiu com o $\mathrm{Ma}$ nifesto dos Pioneiros da Educação Nova (PAGNI, 2000);

- a organização de grupos, como os de defesa da escola pública, contrapondo-se aos defensores da escola particular (XAVIER et al, 1994);

- reformas diversas destacandose, desde a Reforma Capanema (na década de 40) ao acordo MEC/ USAID (que nos legou a Lei no $\div$.540/ 68 e a LDB 5.692/71 entre outras) culminando, no final do século, com a nova LDB no 9.394/96 que é fruto das idéias neoliberais.

Durante esse movimentado processo, também tem sido almejada a formação do perfil de cidadão trabalhador, de modo a atender às novas exigências da Sociedade do Conhecimento Letrado, com sua rapidíssima evolução para o conhecimento informacional. As mobilizações ocorridas somaram-se e responderam às de outras áreas da sociedade que também se agitaram, impulsionadas pelos avanços científico-tecnológicos e pelas relações político-econômicas que aceleradamente se globalizavam.

A sucessão de acontecimentos (gerados por essas demandas) envolveu e foi envolvida pelas mais diversas tendências educacionais desde a Pedagogia Tradicional. Sucederam-na e mesclaram-se a ela todas as demais pedagogias que têm influenciado as gerações brasileiras desde então como, por exemplo, a Pedagogia da
Escola Nova (Diretiva, Não-Diretiva e outras modalidades), a Pedagogia Tecnicista, a Pedagogia Progressista (com suas vertentes) e, no final do século, a Pedagogia da Qualidade e/ ou a Pedagogia de Resultados.

De acordo com Saviani (1984, p. 14), a Escola Nova contribuiu para "desorganizar o ensino" nas escolas da rede oficial e "rebaixar o nível da educação às camadas populares". Isto ocorreu em virtude das conseqüências que a Nova Teoria provocou. Entre elas podemos mencionar o aprimoramento da educação das elites nas poucas escolas experimentais e a não-educação das massas, ao instaurar o afrouxamento da disciplina e o aligeiramento de conteúdos pela secundarização de sua transmissão.

Os primeiros anos da década de 60, de acordo com Xavier (1994, p. 215216), deram continuidade "à tendência modernizadora que já vinha sendo forjada desde meados dos anos 50" (de cunho desenvolvimentista) exigindo a inclusão das massas no processo econômico e político, com reformas de base. Assim, "a primeira metade da década de 60 ficou conhecida no cenário educacional brasileiro como o período dos Movimentos de Educação Popular", com ênfase na alfabetização de adultos, na politização das camadas populares e com o sentido de esclarecer-lhes os seus direitos de cidadãos, para conceder-lhes "voz e vez".

A partir de 1964, com a ditadura militar instaurada no Brasil, prevale- 
ceu a opção política de submissão da economia ao controle do capital internacional e a fiscalização repressiva às manifestações políticas e sociais. A educação escolar, o ideário pedagógico e a vida de muitos educadores foram policiados, dentro e fora das salas de aula. O Serviço Nacional de Informação (SNI) garantiu o controle e a manutenção da ordem, na perspectiva repressora, autoritária e policialesca, adotada pelos poderes governantes. A idade mínima de 12 anos para o ingresso no trabalho infantil (garantida pela Constituição de 1967) dificultou, ainda mais, o acesso e a permanência das crianças oriundas das camadas populares na escola. Esse problema, do trabalho infantil, tem se arrastado historicamente antes e depois desse período, não estando ainda debelado nos dias atuais.

Durante essa época, as desigualdades aprofundaram-se, o analfabetismo aumentou, apesar do discurso de destaque à educação como fator de desenvolvimento. Recorrendo novamente a Xavier (1994) verificamos que: "Tanto as políticas empreendidas de forma global pelo Estado quanto aquelas específicas na área da educação foram gradativamente assimilando a terminologia técnica característica do planejamento consubstanciado pelas idéias de intervenção, controle e racionalização" (Ibid, p. 227). A alfabetização de adultos foi "tratada de forma a neutralizar as experiências ocorridas no início dos anos 60 , consideradas de caráter sub- versivo pelo governo militar" (Ibid, p. 237).

A Pedagogia Tecnicista surgiu como uma evolução dessa tendência racionalizadora e planejamentista, numa tentativa de adequar a educação escolar à questão funcional, organizacional e aos avanços tecnológicos da época, que na escola referiam-se à máquina de escrever - geralmente mecânica - aos mimeógrafos e, quando muito, à utilização de filmes (de rolos). Estes eram raramente utilizados pela inexistência de pessoal especializado para manejar os projetores. Alguns desses aparelhos permaneceram intocados até hoje, na caixa, pelo medo de que fossem danificados. Esta Pedagogia favoreceu a alienação e a estagnação do aprendizado de vivência democrática, prejudicou a organização e a criatividade do pensamento literário das gerações por ela atingidas. Este prejuízo ocorreu porque esta proposta priorizava a esquematização das idéias, refletindo na economia de vocabulário, de organização do pensamento de estilo esquemático, em frases de forma reduzida e causando grandes prejuízos ao aspecto redacional dos alunos.

O combate à alienação instalada com a Pedagogia Tecnicista e suas antecessoras, foi denunciado pelas Pedagogias Progressistas. Recorrendo a Libâneo (1999, p. 32) declaramos que o termo 'progressista', "emprestado de Snyders é usado aqui para designar as tendências que, partindo de uma análise crítica das realidades 
sociais, sustentam implicitamente as finalidades sociopolíticas da educação". Essas idéias pedagógicas apresentaram características críticas, político-sociais e se ramificaram nas tendências: Libertária, Libertadora, Histórico-crítica (defendida por SAVIANI) e/ou Crítico-social dos Conteúdos (assim cunhada por LIBÂNEO, 1985).

De grande florescência entre nós durante a década de 80 , com sua ação política dentro e fora da escola, essas pedagogias despertaram e incentivaram o exercício da cidadania. Estimularam a criticidade e a participação político-social, especialmente das camadas populares, com visíveis resultados obtidos pela força coletiva organizada. Impulsionaram um grande avanço, pela mobilização das camadas populares, em termos de fortalecimento à faceta político-social, despertada no perfil delineador de cidadão para os brasileiros.
No entanto, Assmann (1993) afirma que um "acentuado viés ético-político" marcou a consistência das propostas crítico-sociais, porém faltoulhes avançar na mediação das questões técnico-científicas e político-econômicas. Comenta o autor que essa fragilidade vem favorecendo a sua coexistência no presente "com práticas conservadoras, e pode até servir de cobertura ideológica para corporativismos privados de sérios propósitos educativos" (p. 50).

Vivenciamos esse prognóstico de Assmann durante os anos 90, quando deparamos com os incentivos a uma Pedagogia da Qualidade, que resultou de uma proposta para a melhoria da educação, advinda do setor empresarial brasileiro, representado pela Confederação Nacional da Indústria $(\mathrm{CNI})^{4}$. Esta idéia referia-se à transposição da Filosofia da Qualidade Total ${ }^{5}$ à Educação.

\footnotetext{
${ }^{4} \mathrm{O}$ sistema CNI é constituído pelas seguintes entidades: Confederação Nacional da Indústria (CNI) - entidade sindical patronal, criada em 12 de agosto de 1938; Serviço Nacional de Aprendizagem Industrial (SENAI) - entidade de formação profissional de mão-de-obra para a indústria, criada em 22 de janeiro de 1942; Serviço Social da Indústria (SESI) entidade que presta assistência aos industriários e seus dependentes nas áreas de educação, saúde e lazer, criada em 1 de julho de 1946; Instituto Euvaldo Lodi (IEL) - caracterizado como entidade civil sem fins lucrativos, destinado a promover a interação Indústria/Universidade, criado em 1969 (Cadernos IEL: 1991 - v.1; v.3).

5 "A Filosofia da Qualidade Total, assim considerada e cognominada por estudiosos do setor administrativo, pode ser identificada atualmente por siglas como: TQC (Total Quality Control); ou, em suas versões para o Português: CQT (Controle de Qualidade Total) ou ainda GQT (Gerenciamento da Qualidade Total). Essa filosofia se insere no tema do gerenciamento administrativo desenvolvido ao longo do século; atualmente, constitui-se em uma modalidade de administração empresarial com tendência a generalizar-se mundial mente e, sob a forma como é hoje conhecida, resulta da conjugação de várias abordagens teórico-práticas complementares, que se sucederam e interpenetraram, com mais evidência a partir da década de 40, dando origem a três escolas distintas: americana, japonesa e européia" (MIRANDA, 1995, p. 31).
}

$\overline{238}$ Olhar de professor, Ponta Grossa, 9(2): 229-249, 2006. 
Naquela época, esta proposta foi polemizada e combatida pelos Progressistas; adotada, contudo, por alguns Estados Brasileiros, entre os quais Minas Gerais que se destacou como pioneiro (MIRANDA, 1995) ${ }^{6}$. Apoiada pelos dirigentes do "Metaestado"7, embora aparentemente rejeitada por alguns Estados brasileiros, essa proposta gerou uma pedagogia eclética nas instâncias governamentais do país e no ideário dos educadores em todos os níveis do Sistema Educacional. Temos observado a ocorrência desta afirmação nos discursos orais e escritos de muitos professores.

\subsection{AS IDÉIAS PEDAGÓGICAS BRASILEIRAS NA CONTEMPO- RANEIDADE}

Temos vivido desde a última década, uma fase inquietante no que concerne às tentativas de superação da defasagem em que se encontra o Brasil, em relação às possibilidades de sua inserção na Revolução Microeletrônica e Informacional. É uma fase preocupante, em virtude das mazelas escancaradas sobre a pauperização do sistema educacional brasileiro e do resultado, igualmente deprimente, que atinge a maioria da população.

Mais apreensiva se torna a análise, quando se verifica que as políticas instauradas e as leis promulgadas não obtiveram as soluções propostas. E, mais grave (?!), os montantes financeiros que deveriam solucionar esse caos são desviados por dirigentes corruptos, tão comumente apontados nos escândalos públicos. Desaparece o "ator", o pecúlio e "fica tudo por isso mesmo", diria qualquer representante do povo que fosse entrevistado a respeito.

As perspectivas apontam para um novo jogo de forças, de grupos, de ideologias, para que o Brasil tente cumprir o que está registrado em seu Plano Decenal de Educação (Brasil, 1993) e reafirmam a proposição do Art. 214 da atual Constituição Brasileira de 1988:

Art. 214. A lei estabelecerá o plano nacional de educação, de duração plurianual, visando à articulação e ao desenvolvimento do ensino em seus diversos níveis, e à integração das ações do Poder Público, que conduzam à: I - erradicação do analfabetismo; II universalização do atendimento escolar; III - melhoria da qualidade de ensino; IV - formação para

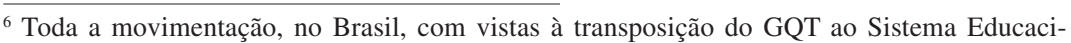
onal Brasileiro, é abordada na Dissertação de Mestrado, sob o título: QUALIDADE/ QUALIDADE TOTAL: EMBRIÃO DE UMA NOVA TENDÊNCIA PEDAGÓGICA ESCOLAR? (Miranda: 1995).

${ }^{7}$ Meta-estado é o termo utilizado por McLaren (1993) para designar o poder dirigente do mundo nos atuais tempos globalizados que se consolidaram no século XX.
} 
o trabalho; V - promoção humanística, científica e tecnológica do País.

Esse Plano tem sido financiado pelos coordenadores do Mundo Globalizado, os "Senhores do Mundo". O que os move e preocupa é a repercussão das nossas mazelas e dos demais países em desenvolvimento e subdesenvolvidos, fora das fronteiras nacionais, por meio das "hordas de bárbaros" que lá chegam. Tais "Senhores" se fazem representar pelo Banco Mundial (para a sustentação financeira) e pela UNESCO (no que tange à recuperação educacional) regidos entre si pelos mesmos princípios (BRASIL, 1994b).

A esses poderes interessa a superação da nossa precariedade educacional por entenderem que, no caminhar do processo de globalização, ela põe em risco a evolução e, até mesmo, a sobrevivência da Humanidade. Para corroborar essas afirmações, revisitaremos as mobilizações por educação ocorridas no Brasil nes- ses nossos tempos contemporâneos. Recorrendo a Sguissardi (2002, p. 240), encontramos a constatação de que:

No final do século XX e limiar do século XXI, a educação superior constitui-se em alvo privilegiado dos que - indivíduos e organizações - vêem o mundo como um imenso e promissor mercado. Campo de sonhadas futuras inversões comerciais, desde o ano de 1994 os serviços educacionais, em especial do ensino superior, constam da agenda da Organização Mundial do Comércio (OMC) como objeto de liberalização competitiva.

Os dois primeiros anos da década de 90, no Brasil, foram marcados com respostas nacionais aos "Senhores do Mundo", por uma significativa aproximação e entrelaçamento entre o setor empresarial e a educação, configurando uma nova resposta. Este relacionamento foi articulado pelo MEC em conjunto com o sistema CNI (Confederação Nacional da Indústria), através do seu Instituto Euvaldo Lodi $(\text { IEL })^{8}$ e contou com a participação de

\footnotetext{
${ }^{8}$ Os 26 anos de atuação do Instituto Euvaldo Lodi (IEL) podem ser delimitados por três períodos, de acordo com Cadernos IEL, v. 1 e 3, 1991 e v. 4, 1992: "o primeiro de 1969 até 1986, foi marcado pelo pioneirismo de estabelecer alternativas para realizar a interação Indústria-Universidade"; no segundo período, de 1986 a 1990, a atuação se fez através de projetos agrupados na forma de programas operacionais que espelham os resultados da interação implementada; o terceiro período, a partir de 1990, edita o Plano Nacional de Interação Indústria-Universidade, "englobando mais de 90 instituições de ensino superior e centenas de executivos empresariais com o suporte do IEL" (v.3. p. 17) e desenvolveu "ações enquadradas nos seguintes programas operacionais: Programa Oficina de Produções (POP), Programa IEL de Competitividade Industrial (IEL-CI) e Programa Educação pela Qualidade" (v.4, p. 5).
}

$\overline{240}$ Olhar de professor, Ponta Grossa, 9(2): 229-249, 2006. 
líderes governamentais (em nível federal) e das Instituições de Ensino Superior (IES), representadas pelo CRUB (Conselho de Reitores das Universidades Brasileiras $)^{9}$.

Essa aproximação entre universidades e empresas tem um sentido de cooperação, de proveito mútuo e ocorre num entendimento de co-participação, visando o desenvolvimento da sociedade. Existe há menos de 30 anos na Europa, nos Estados Unidos e é ainda inoperante no Brasil (MENDES FILHO, 1991; CNI, 1991).

Apesar dessa recenticidade, as relações entre Estado, universidades e empresas, no Brasil, aceleraram-se desde o final da década de 80 e, principalmente, desde o início dos anos 90, culminando com grandes eventos de envolvimento nacional, em resposta a uma "crença transnacional na crescente explicação educacional dos desenvolvimentos e retrocessos nacionais" (RAMIREZ, 1992, p. 414). Essa crença no poder salvacionista da educação, já é repetitiva através da história. Faz parte, hoje em dia, do paradigma mundial de busca e implantação do binômio QUALIDADE ${ }^{10} \mathrm{e}$ PRODUTIVIDADE ${ }^{11}$, para todos os setores da vida na Sociedade do Conhecimento Informatizado que se delineia, com lema e resultados exigidos pela economia internacionalizada.

Com esse entendimento, em cada Estado Brasileiro está sendo processada uma reforma do seu sistema escolar em todos os níveis, apresentando peculiaridades locais, de modo que cada um está "territorializando" a sua educação, no dizer de Barroso (1996), ou seja, imprimindo-lhe características locais. Assim, ocorrem diferentes respostas, conforme as diferentes potencialidades e necessidades, embora tenham em comum as determinações da LDB nº 9.394/96. Também os estudiosos ligados às propostas progressistas para a educação têm apresen-

${ }^{9}$ O CRUB (Conselho de Reitores das Universidades Brasileiras) foi criado em 30/04/66, "é uma sociedade civil, sem fins lucrativos, que congrega, por seus reitores, as universidades brasileiras, qualquer que seja sua natureza jurídica". A filiação é espontânea, sujeita à aprovação do Conselho Deliberativo e mediante o pagamento de taxa de ingresso. O CRUB tem sua sede e foro na Capital da República e terá duração indeterminada (Estatuto do CRUB, 1994, p. 3-4). Atualmente há 90 Universidades filiadas ao CRUB (CRUB, 1995).

${ }^{10}$ Sob o ponto de vista empresarial encontramos vários conceitos, entre os quais destacamos três: (1) "Qualidade é adequação ao uso do consumidor" (Juran, 1990, p. 6); (2) "Qualidade é desempenho do produto e ausência de deficiências." (Idem, 1991, p. 5); (3) Qualidade é tudo que alguém faz ao longo de um processo para garantir que um cliente, fora ou dentro da organização, obtenha exatamente aquilo que deseja, em termos de características intrínsecas, custo e atendimento (Lobo, 1991, p. 16). Essas referências podem ser encontradas em Miranda (1995).

11 "Produtividade é fazer o máximo de quantidade que a qualidade permita" (Barros, 1992, p. 34; ver Miranda, 1995).

Olhar de professor, Ponta Grossa, 9(2): 229-249, 2006. $\overline{241}$ 
tado sugestões, organizado estudos e debates eivados de análises críticas às propostas hegemônicas.

\subsection{PENSAMENTO PEDAGÓGICO E CIDADANIA NOBRASIL}

A pluralidade de discursos sobre educação, proferidos nos últimos anos no Brasil, tem-nos interessado, sobretudo, na verificação das influências e interferências que matizam o pensamento pedagógico brasileiro. Sob o ponto de vista histórico, a prática da educação escolar nem sempre tem se coadunado com as buscas por democracia, embora o século XX tenha sido palco da explosão de várias tendências educacionais em nível mundial. Estas manifestações apresentaram o ensaio de diferentes propostas que se entremearam, sucederam umas às outras e têm convivido, durante a maior parte do século, na cotidianidade das práticas escolares (LIBÂNEO, 1999; SAVIANI, 1984).

Queremos dizer com isto que, as teorias propostas para constarem do pensamento pedagógico brasileiro e serem aplicadas na educação, têm implicações no conceito de cidadania, no perfil e nos direitos do cidadão. Quando se fala nessa questão, pensa-se nos conhecimentos técnicos, literários e científicos da cultura erudita. Não se tem conseguido clareza sobre outros aspectos que devem estar contidos entre as características que definem um cidadão, como: que seja consciente de seus direitos, de- veres, necessidades e possibilidades, dentro da época em que vive e nas implicações desses temas com os relacionamentos sociais.

Entretanto, ainda que não se tenha alcançado o perfil de cidadão integrado ao seu tempo, de forma democrática e com condições de exercer a sua cidadania, ele foi objeto das propostas elaboradas pelas diversas tendências, que se delinearam dentro da realidade educacional mundial, inclusive a brasileira, conforme os entendimentos de cada grupo proponente. A busca deste perfil ganhou força, especialmente com as pedagogias críticas defendidas pelo movimento progressista, nas últimas décadas. Continua-se buscando e propondo sem, contudo, obter-se a concretização do delineamento das idealizações. Vivemos um momento histórico sui generis, de transição, incertezas e mudanças aceleradas, por isso mesmo denominado Pós-Modernidade, que dificulta a consolidação dessas buscas, embora não desqualifique os avanços conseguidos nesse intento.

Impressiona-nos a constatação de Lojkine (1995, p. 11), já citada, de que este momento histórico "acena com uma mutação revolucionária para toda a humanidade" que o autor julga comparável à invenção da roda e da escrita, afirmando que "constitui o anúncio e a potencialidade de uma civilização pós-mercantil". Este anúncio de uma nova civilização que se instala, parece explicar a perplexidade que tem assolado os tempos contemporâne- 
os. A contemporaneidade se abala diante das vertiginosas transformações científicas e tecnológicas, colocadas pelos meios de comunicação, invadindo as casas de todas as camadas sociais, com notícias surpreendentes a todo o momento e no instante em que acontecem, em qualquer parte do mundo.

Não há como negar que as novas tecnologias e as máquinas "inteligentes" executam com perfeição o trabalho de muitos trabalhadores, ameaçando de exclusão até os portadores de altas qualificações, mesmo em países de "Primeiro Mundo". Além disso, as estratégias de terceirização, o trabalho autônomo e o trabalho informal (em casa ou num escritório) em vez de emancipar os trabalhadores, podem camuflar as possibilidades de aumento do desemprego estrutural e crescente, que não é apenas problema brasileiro, mas também mundial e conjuntural, como afirmam Offe (1995); Carmo (1992); Mejía (1995); Bruno et al. (1996); Antunes (1995) e outros autores.

Quanto à educação escolar brasileira, se considerada como um instrumento de busca da consolidação dos ideais democráticos, sua organização é recentíssima. Consta praticamente das últimas décadas, conforme o exposto até aqui e, portanto, ainda tem muito que definir, incluir, superar e instituir.

E hoje?!... Na época da microinformática, em plena revolução informacional (LOJKINE, 1995), a socieda- de do conhecimento, a sociedade letrada, já não consegue admitir o analfabetismo, além das deficiências contidas no perfil incompleto do cidadão (e da ausência de cidadania para a maioria). O mundo e o Brasil se deparam com um problema de extrema gravidade - o analfabetismo funcional não apenas dos que se evadem do sistema, dos que foram rejeitados por ele, mas, por um motivo muito mais catastrófico: os pseudo-alfabetizados. Tais analfabetos funcionais são aqueles que permanecem na escola, percorrem todas as séries e graus do ensino escolar, possuem diplomas, porém, não conseguem utilizar competentemente a língua nacional... "Na prática são incapazes de entender, por exemplo, como funciona o metrô e não conseguem consultar uma lista telefônica ou ler uma bula de remédio" (SINGER, 1995).

E a mobilização em torno do "Programa de Educação para Todos", agitou o início da década de 90, destacou essa nossa mazela ao constituir "as bases dos planos decenais de educação, especialmente dos países de maior população do mundo" (Brasil/MEC, 1993). No grupo que engloba esses países, denominado EFA-9 (Education for All, ou seja, Educação para Todos), além de estarem reunidos os países mais populosos do mundo - incluindo o Brasil - há algumas outras identificações de uns com os outros, através de várias questões (Brasil/MEC, 1993, p. 11). Estas questões os colocam como ameaça aos

Olhar de professor, Ponta Grossa, 9(2): 229-249, 2006. $\overline{243}$ 
destinos individuais e coletivos da humanidade, conforme as palavras do Representante Geral da UNESCO que transcrevemos a seguir:

Juntos, os nove países participantes (desse evento) - Bangladesh, Brasil, China, Egito, Índia, Indonésia, México, Nigéria e Paquistão - constituem mais do que a metade da população mundial, incluindo dois terços dos analfabetos adultos e a maior parte das crianças que não têm acesso à educação. Assim, é evidente que não pode haver progresso global significativo no campo educacional sem progresso em seus próprios países. Como líderes dos países mais populosos do mundo, têm uma responsabilidade muito especial perante a comunidade internacional. O destino da Educação Para Todos está em suas mãos juntamente com tudo o que representa este movimento para o nosso futuro individual e coletivo (BRASIL, 1994b, p. 37).

Esta realidade escabrosa, embora nos coloque em situação gritante, não constitui exclusividade brasileira ou desses nossos parceiros do grupo EFA 9 quanto ao tema que encerra. Há algumas décadas, ela tem sido percebida como parte da conjuntura deste momento histórico em que, até mesmo, as nações do denominado Primeiro Mundo têm-se inquietado com a mediocridade que grassa nos seus próprios fundamentos educacionais e que "ameaça até mesmo o nosso fu- turo como nação e como povo", conforme consta em documento oficial norte-americano sob o título "Uma nação em risco” (EUA, 1983).

Pesquisadores têm apontado, só em Nova York, cerca de dois milhões de indivíduos nessas condições de analfabetismo funcional (SINGER, 1995). Na Inglaterra, recentemente, chegou-se a propor uma volta à palmatória, ao extremo autoritarismo, no desespero de se conseguir resultados qualitativos à educação escolar básica. Está atualmente constatada a deficiência da escolaridade e outras mais no próprio meio dos dirigentes do mundo, não se podendo negar:

- que a educação escolar deve produzir resultados cognitivos, de qualidade compatível e imprescindível a estes tempos paradoxais de competitividade, de busca e manutenção de autonomia;

- que esses resultados apresentam-se embaralhados com o tema da globalização das relações econômicas e de reconfiguração da cartografia geopolítica mundial;

- que os países do Primeiro Mundo rejeitam as "vastas correntes migratórias vindas do Leste europeu e asiático, do Sudeste latino-americano e do Sul africano, continuam cerrados e se cerrando cada vez mais ao que este mundo privilegiado enxerga como hordas de bárbaros" (op. cit.).

Essas "hordas de bárbaros" contêm não apenas elementos da chamada classe média, como também de classes operárias (e até de elite). Tan- 
to uma como as outras, mesmo e apesar de sua escolaridade, migram por não encontrar em condições de qualidade de vida e de trabalho, condizentes com os benefícios que deveriam usufruir dos avanços tecnológicos e da época presente, em seus países de origem.

Diante da atual crise, a conjuntura do mundo contemporâneo aponta como solução a obrigatoriedade da educação básica até ao final do Ensino Médio. Nos classificados de jornais, os mais variados, as ofertas de emprego apontam para uma generalização de exigências básicas de $2^{\circ} \mathrm{Grau}$ (Ensino Médio) completo para o exercício de tarefas que, até bem pouco tempo, eram satisfeitas por funcionários com $1^{\circ} \mathrm{Grau}$ (Ensino Fundamental), geralmente incompleto. No que se refere às políticas educacionais dos países em desenvolvimento, indicase a educação e a produção do conhecimento científico na educação escolar, como recurso instrumentalizador de ações detentoras da competência hoje requerida, como "eixo da transformação produtiva com eqüidade", o que foi tratado em extenso documento que leva este título (CEPAL/UNESCO, 1992).

Em que pese a incontestável importância do conhecimento, como informação que subsidie a realização de qualquer tipo de ação, questiona-se a necessária consistência que o mesmo deva conter, para que não seja apenas técnico, científico, imediatista. Para tanto, precisa agregar a essas condições, outras que contemplem posicionamentos críticos, éticos, políticos e de repercussão social. Essas análises apontam para uma nova fase de maturidade, no aperfeiçoamento da estrutura que compõe o pensamento pedagógico brasileiro.

Entretanto, as propostas de modernização das sociedades, coordenadas pelos "Senhores do Mundo" (CHOMSKY, 1993), têm contemplado a educação de massa com ênfase na escolaridade e habilidades cognitivas básicas: linguagem, ciências, matemática, como instrumentos de resolução de problemas técnicos e de comunicação nos relacionamentos. Estudiosos dos documentos oficiais como Demo (1997) e Lauglo (1997), por exemplo, alertam para o fato de que os proponentes não atentam para as questões morais e sociais, além de apresentarem o significado de "habilidades de comunicação" de forma obscura.

A mídia tem divulgado amplamente as negociações e pressões enfrentadas por dirigentes brasileiros e de outros países, nos últimos anos, no sentido de se adaptarem à atual fase de relações políticas e econômicas globalizantes. As adequações são realizadas de acordo com as determinações das organizações internacionais, dirigentes do mundo. Entre as questões, julgadas importantes para sofrerem as adaptabilidades, incluem-se as que se referem à reorganização da educação e do seu pensamento pedagógico. Na última década, esta

Olhar de professor, Ponta Grossa, 9(2): 229-249, 2006. $\overline{245}$ 
conotação evidenciou-se nos projetos de "Educação Para Todos" (BRASIL/MEC, 1994a/b).

Essas propostas, além da extensão do direito à educação escolar, tentaram incorporar os avanços científicos e tecnológicos informatizados, requerendo presteza à solução de antigos problemas, incluindo questões preocupantes e que se interligam como, por exemplo, a dualidade (historicamente colocada), entre o ensino médio generalizante e o profissionalizante. Os legisladores agem como se tivessem conseguido superar todas essas questões. Desconsideram as questões concretas, referentes à baixa renda das camadas populares, que requerem o trabalho remunerado precocemente, na infância e na adolescência. O máximo que tem sido oferecido compõe-se de medidas precariamente compensatórias, vexatórias e instaladoras de baixa estima, produzindo sensações de menos-valia, de alienação sobre o valor do ser humano e distanciando-o do conceito de cidadania.

Além dessas questões, o documento que registra a nova Lei de Diretrizes e Bases Para a Educação Nacional (LDB n 9.394/96) espelha as propostas de reorganização do sistema educacional brasileiro, em todos os graus de ensino, advindas das políticas do MEC, em consonância com os ditames das organizações internacionais. Nossa nova Lei da Educação Nacional reflete, também, as propostas educacionais que estão sendo implantadas em cada um dos Estados e Municípios da Federação. Alguns deles antecederam a própria Lei, reorganizando os seus sistemas educacionais no início da década de 90. Como exemplo, citamos Minas Gerais, Mato Grosso e Paraná - impulsionados pela mobilização por qualidade em escala planetária que ocorria nessa época (MIRANDA, 1995). Essa antecipação confirma o que dissemos anteriormente, no sentido de que já se sabia quais eram as modificações desejáveis à Nova Ordem Mundial (Idem).

\section{CONCLUSÃO}

Entendemos que, além dessas nossas reflexões, muitas outras questões educacionais demonstram o quanto a educação escolar ainda é incipiente e, conseqüentemente, o pensamento pedagógico brasileiro também o é. Questões esta que merecem e devem ser abordadas em ocasião propícia. Entre elas, ocorre-nos listar, por exemplo: a necessidade de valorização do magistério; a responsabilidade estatal para com a Educação Infantil de zero a seis anos; o direito à Educação Especial e à inclusão escolar e social para os portadores de deficiências de qualquer ordem; a humanização do ensino noturno; a seriedade para com a Educação de Jovens e Adultos... Muitas outras podem e devem ser incluídas entre essas preocupações, o que reforça nossa análise do quanto ainda há que construir, 
desmistificar, desfazer preconceitos e integrar no campo educacional.

Retomando nossas constatações, estes e tantos outros temas, que se pode facilmente citar, evidenciam que a nossa situação educacional, ainda se encontra plena de precariedade, no que se refere a uma educação emancipatória para a maioria do povo brasileiro. Entretanto, pode-se encontrar algumas "ilhas de excelência", representadas por escolas de elite, que nada deixam a desejar, quando comparadas com a educação de países do chamado Primeiro Mundo. Essas constatações apresentam-se como relevantes para que sejam documentados os aspectos da evolução na área da educação escolar e que remetem ao tema proposto, ou seja, para que se verifique a expressão do pensamento pedagógico brasileiro nos contextos regionais e locais nos tempos contemporâneos.

Esta época atual, de transição pósmodernidade, tem colocado o desafio de enfrentar as necessidades de mudança social, diante das exigências de conhecimento produzidas pela evolução tecnológica. A incitação gerada por esta fase apresenta-se com alguns matizes de expectativa em direção a um aperfeiçoamento que, além do preparo técnico, acarreta o anseio e a busca contínua de compreender os tempos novos, e de exigir cada vez mais e maior qualidade à vida de modo geral. Entre estas expectativas, encontra-se a exigência de atualização e a possibilidade de emancipação.
Ao mesmo tempo, a direção apontada pelas tendências manifestas, percebidas ou não, cria certa apreensão tanto pelo não-conhecido como pela destruição do passado ou pelo temor de que os resultados futuros não se tornem satisfatórios, se e quando as tendências se transformarem em práticas sociais atuantes. Esse conjunto de questões, cada dia mais aponta para a ampliação das fronteiras colocadas por antigos conceitos e delimitações.

A interdependência historicamente imposta, pelos governantes do mundo globalizado, estabelece o delineamento orquestrado de políticas nacionais. Como já dissemos, os reflexos dessa Nova Ordem Mundial influenciam e interferem na governabilidade dos países em desenvolvimento e na organização de seus sistemas educacionais. Os imperativos, dessa fase histórica, os impelem a se adequarem aos parâmetros requeridos por esses tempos contemporâneos, acrescentam-lhes novas e incontestáveis provocações em todos os setores da sociedade, entre os quais se inclui a educação e a tentativa de aprimoramento do(s) pensamento(s) pedagógico(s) que a sustentam.

\section{REFERÊNCIAS}

ANTUNES, R. Adeus ao trabalho? Ensaio sobre as metamorfoses e a centralidade do mundo do trabalho. São Paulo: Cortez, 1995.

ASSMANN, H. Paradigmas educa- 
cionais e corporeidade. Piracicaba: UNIMEP, 1993.

BARROSO, J. PEPT 2000: da exclusão escolar dos alunos à inclusão social da escola: que sentido para a territorialização das políticas educativas? In: FORUM NACIONAL DE PROJETOS, Contra a Exclusão, Actas... Lisboa, 1996.

BRASIL. Lei n. 9394/96, de 20 de dezembro de 1996. Estabelece as Diretrizes e Bases para a Educação Nacional. Diário Oficial, n. 248, Brasília, 23 dez. 1996.

BRASIL. Ministério da Educação. A Conferência de Nova Delhi: educação para todos. Brasília: MEC, 1994.

. Ministério da Educação. Secretaria de Educação Fundamental. Conferência Nacional Educação para Todos. Brasília: MEC/SEF, 1994b.

Ministério da Educação. Plano Decenal Educação Para Todos. Brasília: MEC, 1993.

BRUNO, L. (Org.). Educação e trabalho no capitalismo contemporâneo: leituras selecionadas. São Paulo: Atlas, 1996.

CANO, W. Reflexões sobre o Brasil e a nova (des)ordem internacional. 3. ed. Campinas: UNICAMP,1994.

CARMO, P. S. A ideologia do trabalho. São Paulo: Moderna, 1992.

CHOMSKY, N. Os novos Senhores da humanidade. Folha de São Paulo, São Paulo, 25 abr. 1993. Caderno Mais, p. 618.

CONFEDERAÇÃO Nacional da Indústria - CNI. Cadernos IEL. Rio de Janeiro: IEL, 1991. (Volumes 1 e 3).

DEL ROIO, M. T. O império universal e seus antípodas: a ocidentalização do mundo. São Paulo: Ícone, 1998.
DEMO, P. A nova LDB: ranços e avanços. 3. ed. Campinas: Papirus, 1997.

ESTADOS UNIDOS DA AMÉRICA. Departamento de Educação. Comissão Nacional sobre Qualidade da Educação. Uma nação em risco. Tradução de Hugo Assmann e Melsene Ludwig. Porto Alegre, abr. 1983. (Texto digitado).

FREITAG, B. Análise crítica das políticas educacionais no Brasil. Dois Pontos, Belo Horizonte: v. 2, n. 19, p. 20-27, 1994.

FRIGOTTO, G. A produtividade da escola improdutiva: um (re)exame das relações entre educação e estrutura econômico-social e capitalista. São Paulo: Cortez, 2001.

IANNI, O. A sociedade global. Rio de Janeiro: Civilização Brasileira, 1992.

KURZ, R. O colapso da modernização: da derrocada do socialismo de caserna à crise da economia mundial. 4. ed. Tradução de Karen E. Barbosa. Rio de Janeiro: Paz e Terra, 1993.

LAUGLO, J. Críticas às prioridades e estratégias do Banco Mundial para a educação. Cadernos de Pesquisa, São Paulo, n. 100, p. 11-36, mar. 1997.

LIBÂNEO, J. C. Democratização da escola pública: a pedagogia crítico-social dos conteúdos. 16. ed. São Paulo: Loyola, 1999.

LOJKINE, J. A revolução informacional. São Paulo: Cortez, 1995.

MACHADO, M. S. A lógica da reprodução pentecostal e sua expressão espacial. In: SANTOS, M. et. al. (Orgs.). Fim de século e globalização. São Paulo: Hucitec, 1994.

MCLUHAN, M. Revolução na comunicação. Rio de Janeiro: Zahar, 1968. 
MEJÍA JUNIOR, M. R. Educacion y escuela en el fin de siclo. Bogotá, Co: CINEP, 1995.

MENDES FILHO, A. Universidade-empresa: pelo fim dos preconceitos. Impulso, Piracicaba, v. 5, n. 10, p. 71-79, 1991.

MIRANDA, M. F. A expressão do pensamento pedagógico brasileiro na realidade histórica da educação na cidade de Londrina, Paraná. Londrina: UEL, 2001. (Projeto de Pesquisa)

Num quintal da globalização: reflexos do processo de ocidentalização do mundo na educação brasileira de ensino médio. Tese (Doutorado) - Universidade Estadual Paulista, Marília, 2000.

Qualidade/qualidade total: embrião de uma nova tendência pedagógica escolar? Dissertação (Mestrado). Universidade Metodista de Piracicaba, Piracicaba, 1995.

OFFE, C. Capitalismo desorganizado: transformações contemporâneas do trabalho e da política. 2. ed. São Paulo: Brasiliense, 1995.

PAGNI, P. A. Do Manifesto de 1932 à construção de um saber pedagógico: ensaiando um diálogo entre Fernando de Azevedo e Anísio Teixeira. Ijuí, RS: UNJUI, 2000.

PONCE, A. Educação e luta de classes. 14. ed. Tradução de José S. de Camargo Pereira. São Paulo: Cortez, 1995.

RAMIREZ, F. A institucionalização e globalização do estado-nação: cidadania e mudança social. Estado e Sociedade, Campinas, n. 43, p. 413-437, dez. 1992.

SANTOS, M. et al. Fim de século e globalização. 2. ed. São Paulo: Hucitec, 1994.
SAVIANI, D. Escola e democracia. 5. ed. São Paulo: Cortez, 1984.

SGUISSARDI, V. Rumo à universidade competitiva: na modernização conservadora a universidade perde a sua face, sua alma e sua identidade históricas. Perspectiva, Florianópolis, v. 20, n. 2, p. 239268, jul.-dez. 2002.

SINGER, P. Poder, política e educação. In: REUNIÃO ANUAL DA ANPED, 18 , Conferência de abertura, Caxambu, 1995.

UNESCO. Educación y conocimiento: eje de la transformación con equidad. Santiago, Ch: CEPAL/UNESCO, 1992.

XAVIER, M. E. S. P. et al. História da Educação: a escola no Brasil. São Paulo: FTD, 1994.

Encaminhado em: 07/07/06

Aceito em: 15/08/06 